Max-Planck-Institut für demografische Forschung

Max Planck Institute for Demographic Research

Doberaner Strasse $114 \cdot$ D-18057 Rostock $\cdot$ GERMANY

Tel +49 (0) 3812081 - 0; Fax +49 (0) 3812081 - 202;

http://www.demogr.mpg.de

MPIDR WORKING PAPER WP 2001-026

AUGUST 2001 (REVISED JANUARY 2002)

\title{
Opposite effects of maternal and paternal grandmothers on infant survival in historical Krummhörn
}

Eckart Voland (eckart.voland@phil.uni-giessen.de)

Jan Beise (beise@demogr.mpg.de)

This working paper has been approved for release by: James W. Vaupel (jwv@demogr.mpg.de)

Head of the Laboratory of Survival and Longevity.

(C) Copyright is held by the authors.

Working papers of the Max Planck Institute for Demographic Research receive only limited review. Views or opinions expressed in working papers are attributable to the authors and do not necessarily reflect those of the Institute. 
Opposite effects of maternal and paternal grandmothers on infant

\title{
survival in historical Krummhörn
}

\author{
Eckart Voland ${ }^{1,3}$ and Jan Beise ${ }^{2}$
}

${ }^{1}$ Zentrum für Philosophie und Grundlagen der Wissenschaft, Universität Giessen,

Otto-Behaghel-Strasse 10C, D-35394 Giessen, Germany

eckart.voland@phil.uni-giessen.de

phone: (+)49-(0)641-99-15550

fax: (+)49-(0)641-99-15509

${ }^{2}$ Max-Planck-Institute for Demographic Research

Doberaner Strasse 114, D-18057 Rostock, Germany

Beise@demogr.mpg.de

${ }^{3}$ to whom correspondence should be addressed 


\begin{abstract}
On the basis of church register entries from the Krummhörn region (Ostfriesland, Germany, 1720-1874) we looked at the question whether the existence or non-existence of grandmothers had an impact on the reproductive success of a family. We found that fertility (measured by intervals between births) was not influenced by grandmothers. However, maternal grandmothers tended to reduce infant mortality when the children were between six and twelve months of age. During these six months, the relative risk of dying was approximately 1.8 times higher if the maternal grandmother was dead at the time of the child's birth compared to if she was alive. Interestingly, the existence of paternal grandmothers approximately doubled the relative risk of infant mortality during the first month of life. We interpret this as being the result of a tense relationship between mother- and daughter- in-laws. We found that Krummhörn grandmothers could be both helpful and a hindrance at the same time. Geographic proximity tended to increase the effects found. If this ambivalent impact of grandmothers on familial reproduction could be generalized beyond the Krummhörn population, the hypothesis that the evolution of the postgenerative life span could be explained by grandmotherly kin-effects would have to be stated more precisely: the costs of social stress in the male descendency would have to be subtracted from the benefits of aid and assistance in the female descendency. At any rate, the Krummhörn data do not offer a role model for grandmothers who provide unconditional assistance, an effort which in itself could have explained the evolutionary extension of the human life span.
\end{abstract}

\title{
Key words
}

„grandmother hypothesis“, Krummhörn, human evolutionary reproductive ecology, helping, infant mortality, life history theory, "evil mother-in-law" 


\section{Introduction}

Human female life history, as opposed to the typical ape life history, is characterized by a pronounced postgenerative life span. Controversy abounds regarding the adaptive reasons which have led to an extension of the life span during human evolution. One particular point of controversy has been the question whether this is primarily a male-driven or a femaledriven phenomenon. The life span may have been extended for reasons such as those set out in the "difficult-to-acquire-food hypothesis", for example (Kaplan 1997, Kaplan et al. 2000). According to Kaplan's model, the catalytic trigger for an extension of the life span came primarily from the increasing productivity of male subsistence strategies, mostly hunting, in conjunction with other complex, interacting factors. Marlowe (2000) formulates the "patriarch hypothesis“" as an explanatory model for the increase in the human life span. In this model, the extension of life is seen as a male-driven phenomenon, too - although for different reasons.

Other scenarios have been drafted, however, where it was assumed that early hominid females had crucially expanded their subsistence strategies following Pleistocene climatic changes, e.g. by including nutritious tubers in their diets which had to be dug up from the ground. By this means, older women were able to make a net contribution to the reproduction of their kin. Specifically, ageing females, whose own fertility was declining to zero, could increase the fertility of their daughters by providing food for weanlings that the mothers themselves could not handle effectively. As a result, the weaning age decreased and hence interbirth intervals became shorter if compared with the life history of apes, where there was no grandmaternal help (Alvarez 2000, Blurton Jones et al. 1999, Hawkes et al. 1998, O’Connell et al. 1999).

Regardless of how the evolution of the extended life span may have occurred, the timing of the menopause appears to have remained unchanged. While human and chimpanzee longevities differ, the fecund life span of the human female is similar to that of chimpanzees. 
The obligatory menopause in the fifth decade of life may thus be seen as phylogenetic inertia, deeply rooted in mammalian reproductive physiology, the evolutionary reorganization of which could not easily succeed (Kaplan 1997, Leidy 1999). On the other hand, the stock of oocytes would be large enough to last to age 70 . The observation that due to an acceleration of atresia that occurs before age 40 , women run out of oocytes at about age 50 conveys the impression of adaptive design. Thus it seems not unlikely that the menopause might be an hominid adaptation instead of a fixed constraint of mammalian physiology (Peccei 2001a,b, see however Leidy et al. 1998).

Despite inevitable sterility in old age, investment in an extended life span is worthwhile, on average, if older women are able to increase the lifetime reproductive success of their own adult offspring by providing economic or social support. Ancestral senior females who were still fairly vigorous when their own fertility had dropped, could increase the number of surviving children born by their daughters, simply by helping out. This is an evolutionary route through which a life history like those of living chimpanzees would be moved out of a typical ape equilibrium and toward the life histories we see in all humans today (Hawkes et al. 1998, see Peccei 2001a for a critical evaluation of Hawkes's hypothesis on the evolution of the human female life history).

A related but conceptually distinct question is whether the help provided by postmenopausal women has been able to increase inclusive fitness more so than a theoretically assumed continuation of their own reproduction in view of the costs of reproduction that rise with age. This is the issue that Williams (1957) raised in his classic paper, namely whether the menopause is deemed to be more of an "adaptive choice" than a constraint. Hill and Hurtado (1996) pursued this question during their study of the Ache people. Even if they found some evidence that older women are actually able to increase their fitness on average if they discontinue their own reproduction and instead support their children with their reproduction, the authors tend to remain skeptical due to the relative 
insignificance of the effect they have found. They surmised that there are other, still unknown reasons for the evolution and persistence of the menopause (see also Hill and Hurtado 1997). Mace (2000) and Peccei (2001a,b) rightly pointed out that the cost-benefit matrix of the menopause could be influenced in more complex ways than was assumed in previous models. Anyway, if the menopause is indeed an adaptation for increased investment in already existing offspring, this is likely to involve mainly maternal, not grandmaternal investment (Peccei 2001a,b).

Apart from the question of the evolution of the menopause, it remains for sociobiological and behavioral ecology researchers to clarify under what socio-ecological opportunity structures grandmotherly assistance assumes which form and which degree. Thus Hawkes et al. $(1989,1997)$ described hard-working Hadza grandmothers who engage in the acquisition of food with much more effort than the younger, reproductive women do. The help from grandmothers relieves somewhat their adult daughters (or other female relatives) from subsistence tasks, allowing them to increase reproductive investment instead.

Bereczkei (1998) showed for Hungarian Gypsies that child-caring grandmothers increase the fertility of their daughters. An analysis of the anthropometric and vital statistics data from a rural farming population in Gambia carried out by Sear et al. points to the special function of maternal grandmothers (2000, in press). Provided that they were not reproducing any longer, their presence correlated with the dietary condition (measured by body height) and significantly higher survival chances of their grandchildren. No such effect was discernible if where the grandmothers had not yet discontinued their own reproduction. Thus there is a strong indication for an allocation conflict between investment in one's own offspring versus kin investment. Interestingly enough, despite the patrilineal and patrilocal sociology of the Gambian communities, the paternal grandmothers did not play any helping role in the reproduction of their daughters-in-law. 
With this study, we intend to estimate the degree of grandmaternal assistance in the historical population of Krummhörn (Ostfriesland, Germany, $18^{\text {th }}$ and $19^{\text {th }}$ centuries) in order to obtain knowledge about grandmaternal assistance in another socio-ecological scenario. We pursued this objective by examining the impact of grandmothers on the survival chances of their grandchildren and the fertility of their daughters (measured by interbirth intervals and parity progression ratios).

\section{Methods}

Data

We have evaluated the church registers of the Krummhörn region (Ostfriesland, Germany, 18th-19th centuries), as well as tax rolls and other records, using the wellestablished method of family reconstitution employed in historical demography (Voland 2000). At present, we have completed the data collection for 19 of the 32 parishes in this region. Although a few parish registers have been kept since the 17th century, data could not be considered reliable until the 18th century, when partial under-registration (especially of stillborn children and early infant deaths) could be ruled out.

After having documented all the church book entries, we reconstituted the family structures. Our goal was to ascertain that the genealogical linkage as completely as possible for individual stem families over several generations. At present, we have vital and social data available from slightly more than 23,000 families. A summary of some of the main results of the Krummhörn study is given in Voland (1995).

At the end of the 19th century, the marsh regions to which the Krummhörn belongs covered only $7 \%$ of the total area of the Hanover province, but they produced $22 \%$ of its agroeconomic output (Meitzen 1894). In contrast to the neighboring heathland and moor regions, large and medium-sized businesses dominated the farming economy. A capital and market- 
oriented agriculture was able to develop and replace a pure subsistence economy in the Krummhörn earlier than elsewhere in Germany. Accumulation of proceeds was possible and indeed led to remarkable wealth concentration in some lineages. Consequently, a "two-class society" developed with big farmers on the one hand, who owned both the land and the capital, and a large mass of landless workers and rural craftsmen without property on the other. This division of society is also reflected in the reproductive strategies of the Krummhörn population. While the relatively prosperous farmers manipulated the fate of their children in accordance with the logic of a resource competition scenario (Beise 2001, Voland and Dunbar 1995), the masses of workers dealt with fertility „opportunistically“, i.e. the sex of the children and the family size already attained were irrelevant to their investment decisions. Consequently, infant mortality does not show any remarkable variability in these families. This is why we concentrated on the landless segment of the Krummhörn population in this study; any potential grandmother effects would presumably not be overshadowed by economically motivated investment decisions here.

\section{Sample selection}

We have considered only the data of children

- $\quad$ from non-prosperous families (i.e. from families owning less than 75 grasen of land, 1 gras $\cong 0.37$ ha. This segment of the population consists primarily of farm workers, simple rural craftsmen, small tradesmen and farmers below the subsistence threshold)

- $\quad$ from completely known families (i.e. beginning and end of marriage are "under observation" which makes it most likely that the whole reproductive history in between these two events is known for this family as well, for criteria see Voland and Dunbar 1995)

- $\quad$ whose birth dates are precisely known 
who were born between 1720 and 1874

who were born alive

whose mothers survived at least the first two years post-partum, i.e. when most children can be expected to have been weaned (Kaiser 1998)

\section{Dependent variables}

infant survival during first five years of life (excl. stillbirths)

interbirth intervals (between two successive live births)

parity progression (only if the index child has survived the first year of life: if another birth (live birth or stillbirth) follows, then $\mathrm{pp}=1$, if the index child remains the last in the sequence of siblings, $\mathrm{pp}=0$ )

\section{Independent variables}

number of siblings alive at the birth of the index child

constellation of grandmothers at birth of the index child. Reference group: both grandmothers are dead. Dummy variable 1: only the paternal grandmother is alive, dummy variable 2: only the maternal grandmother is alive, dummy variable 3: both grandmothers are alive (the construction of dummy variables describing the four possible outcomes of two binary variables is a simple way of considering interaction effects between these two variables) constellation of grandfathers at birth of the index child. Reference group: both grandfathers are dead. Dummy variable 1: only the paternal grandfather is alive, dummy variable 2: only the maternal grandfather is alive, dummy variable 3: both grandfathers are alive 
places of residence. Reference group: the natal family and the two families of grandparents have the centers of their lives in the same community (see Beise 2001 regarding the method for determining the "center of life"). Dummy variable 1: neither of the two grandparent families have the center of their lives at the place of residence of the natal family, dummy variable 2: only the paternal grandparents have the center of their lives at the place of residence of the natal family, dummy variable 3: only the maternal grandparents have the center of their lives at the place of residence of the natal family Age of the mother $($ mean $=31.77 ; \mathrm{sd}=6.03 ; \mathrm{n}=9447)$ Age of the father $($ mean $=34.76 ; \mathrm{sd}=7.14 ; \mathrm{n}=9084)$ Year of birth

Square of the year of birth

\section{Results}

Grandmaternal impact on fertility (interbirth intervals)

As expected, interbirth intervals became longer the higher the age of mothers and fathers, while they became shorter the larger the family. The presence or absence of grandmothers (or grandfathers) had no effect at all on interbirth intervals (Tab. 1). We were also unable to ascertain any stable interaction effects between the constellation of the grandparents and the age of the mother or the family size. Quite obviously, grandmothers do not influence the interbirth intervals of their daughters or daughters-in-law, and also do not exert any influence on mothers in certain age groups or in especially large families, for example. 
Tab. 1

Grandmaternal impact on fertility (parity progression probability)

Table 2 shows how the probability of having another child depends on a set of independent variables. Parity progression probabilities were only ascertained for children who had become at least one year old, in order to rule out, for the greater part, the effects of any replacement strategies. Moreover, the grandmother constellation two years after the birth of the last-born child was taken into consideration, because it is assumed that grandmaternal assistance, especially during the first years of life, could influence the decision for or against another child. It is also assumed that this decision will not already have been made at the birth of the youngest child.

Tab. 2

As expected, the age of the mothers and fathers and the already attained size of the family influence the probability of having another child. Over and above this, there is a marginally significant grandmother effect: If both grandmothers are still alive, this tends to increase the probability of another birth $(\mathrm{p}=0.0644)$; note however that the overall grandmother constellation effect is not significant ( $\mathrm{p}=0.2359$ ). Interestingly, the positive effect of both grandmothers being alive on parity progression ratios is particularly marked in large families (Tab. 3). 
Tab. 3

\section{Grandmaternal impact on infant survival}

Infant survival was analyzed for the first five years of life. Figure 1 shows the plotted estimated survival functions (Kaplan-Meier estimates) of the children grouped by the four possible constellations of grandmaternal survival. The survival was highest for those children whose maternal grandmother was alive at the time of birth, irrespective of the status of the paternal grandmother. Interestingly, the lowest probability for survival was that of children whose only surviving grandmother was the paternal one. The survival probability of children without any grandmother was almost half way between those extremes.

Fig. 1

In order to control for the covariates, a parametric transition rate model was applied. The following analyses are based on piecewise constant exponential models (Blossfeld and Rohwer 1995). These models are the simplest of the parametric transition rate models but show great flexibility. Instead of making strong assumptions about the time-dependency of the process, the piecewise constant exponential models simply split the time axis into time periods and assume that the transition rates in each period are constant but allow the rates to change freely from one interval to the other. Since it cannot be assumed that a potential grandmaternal influence on survival is proportional over all periods of time, the model was 
adapted for period-specific effects (Blossfeld and Rohwer 1995), i.e. the effects of the covariates were estimated separately for every defined time period. Since transition rate models are based on events, the following models do not actually analyze infant survival but infant mortality.

Table 4 summarizes the results of this approach. It shows the relative death risk for children without living maternal and paternal grandmothers, respectively, at the time of birth compared to those children with a respective grandmother living. These relative risks are estimated separately for every period. When referring to the first model, for instance, the risk of dying between age 6 and 12 months was 1.62 times higher for children whose maternal grandmother was already dead (at the time of birth) than for children whose maternal grandmother was alive (with $\mathrm{p}<0.05$ ). In order to avoid any confounding effects which may have occurred due to the mortality of nursing mothers, only those children were considered whose mothers survived at least the first two years. It can be assumed that after two years most children were weaned (Kaiser 1998).

Tab. 4

The first model includes the grandmothers' status only and is therefore roughly equivalent to the plotted survivor functions in figure 1 . The influence of the maternal grandmother on infant survival was predominantly positive as shown at the relative risks greater than 1 (actually, the positive effect was that of a dead grandmother on the child's mortality but this is awkward to deal with, therefore the reverse but identical interpretation is used). The influence was greatest in the period representing an age of 6-12 months $(p<0.05)$ and in the following age period representing the second year of life. The paternal grandmother had much less positive effects on the child's survival: the relative risks are more often close to 
1 (meaning no effect) and in the very first month the effect is even negative $(\mathrm{p}<0.05)$, meaning that the risk of dying was greater for those children with a living paternal grandmother compared to those without.

In model 2, the age of the mother and the number of living siblings were included as covariates, since these variables are known to have a significant impact on infant mortality. Besides these variables, the model controls for the constellation of grandfathers (in design analogous to the 'constellation of grandmothers') and the birth cohort (in order to test for the influence of historical, social and environmental changes). In controlling these variables, the pattern of effects does not change much.

In model 3, two further dummy variables were included which indicate a joint parish of residence of the child's family with its maternal grandmother and its paternal grandmother, respectively. These variables were included in order to control for the potential effects of geographical proximity, although the consequences of this proximity are not clear (see discussion). In the Krummhörn region, the general pattern of residence was male-biased although this did not apply to all families (Beise 2001). The inclusion of these variables of residence intensified the observed effects. For children without living maternal grandmother, the relative risk of dying within the age period 6 to 12 months increases by $79 \%$ compared to children with a living maternal grandmother, and it increases by $43 \%$ in age period of 1 to 6 months. The negative effect of the paternal grandmother is also greater than in the previous model and indicates almost a doubled death risk for the child if the paternal grandmother was alive compared to if she was dead. A further effect can be observed in the 36 to 60 months period - although a positive one.

In order to further analyze the potential influence of geographical proximity, model 3 was re-estimated by replacing the grandmother and the residence variables with new variables, combining both sets of information (Table 5). Four different combinations of the grandmother's existence and her residence are possible, from which only three are of interest: 
1, the grandmother lives in the same parish; 2 , the grandmother lives in a different parish; 3 the grandmother is dead (no matter where she had lived). Introducing the first two groups as dummy variables - each for both grandmothers separately - and using the third category as the reference group, the picture gets slightly more complicated but for the most part still corresponds to the previously described pattern: a maternal grandmother living in the same parish as her grandchild decreased the child's death risk by 39\% in the age period of 1 to 6 months and by $33 \%$ in the period of 6 to 12 months compared to a dead grandmother although only the first effect tends to reach a level of significance worth mentioning. In contrast, a grandmother living in a different parish (but still in the same region) decreased the mortality in the age period of 1 to 6 months by "only" 18\%. In 5 out of 6 age classes the presence of the grandmother in the parish of their daughter's family tends to intensify her positive effects on infant survival.

Also, the negative effect of the paternal grandmother emerges again: her presence in the same parish increased the death risk for her grandchild in the very first month by almost $150 \%$, her presence in another parish by $59 \%$. There is another negative effect in period 5 (for paternal grandmothers in the same parish) and a positive effect in period 6 (for paternal grandmothers in a different parish).

Table 5 


\section{Discussion}

The entries in the church registers document that Krummhörn grandmothers of the 18th and 19th centuries increased the survival chances of their grandchildren. Grandfathers, however, did not - a result that parallels the findings of Sear et al. (in press) for a Gambian farming population. Still, the overall degree of grandmaternal assistance is modest. It is only the maternal grandmother whose existence increases significantly the survival chances of her grandchildren, and this only if the grandchild is between 6 and 12 months of age. In only a very limited sense can we say that maternal grandmothers were able to increase the reproductive success of their daughters.

It remains unclear through what kind of behavioral interactions this effect came about. At best, historical church records can reveal the consequences of behavior for human life history, but naturally not the behavior itself. It is well known, though, that mothers often helped with the first delivery of their daughters. Consequently, the place of birth of the first child of a family is often the place of residence of the maternal grandmother and not of the young family (Beise 2001). It seems unlikely, however, that this tendency towards birth assistance could cause increased infant survival chances in the second half of the first year of life. The timing of the positive grandmother effect rather suggests that helping became significant especially in the weaning process. Perhaps during the first six months of life, grandmothers had only few chances to help due to maternal breastfeeding. With weaning, however, the opportunities for grandmaternal nepotism might have gained in importance. What grandmothers really did, remains unknown. Presumably, economic fluctuations and variations in the amount of housework or gardening could be buffered by grandmothers. Also, the transfer of knowledge of how to handle infant health problems might have been relevant here. However, these assumptions remain speculations, since we have no data on behavioral 
interactions or material transfers in the grandmother-mother-infant triad and how these might have influenced the outcome of the weaning process.

Geographic proximity of grandmothers to the families of their offspring had some significance. If grandmothers lived in the same parish as their daughters, the help they provided gained slightly in effect, although the mere existence of a grandmother had a much higher significance. As a consequence of the selection criteria for the sample, all grandmothers lived in the neighboring villages of the Krummhörn region, i.e. even grandmothers who did not share the parish of residence with their grandchildren lived not too far away. Sources from the first half of the nineteenth century cite travel distances between less than half an hour for neighboring parishes and a few hours for an average distance in this sample. Thus the distance between the villages of different parishes were not too great to prevent frequent mutual visits. Under these circumstances, support (or mobbing, for that matter) did not necessarily require a permanent physical presence.

It is interesting to note that the interbirth intervals are not influenced by grandmothers. Only in very large families, which tended to be the exception in the Krummhörn, did grandmothers facilitate the decision to have another child, and only if both grandmothers were still alive. The finding that grandmothers do not ensure increased fertility appears not to follow one of the core assumptions of the "grandmother hypothesis" (Alvarez 2000, Hawkes et al. 1998). Yet it is clear that whatever the Krummhörn data reveal, they are not suitable for a hard test of the grandmother hypothesis. The living conditions of historical Krummhörn families of laborers and craftsmen certainly bear little resemblance to the Pleistocene conditions of human life history evolution.

The lack of a grandmaternal effect on fertility is probably not due to a lack of motivation for material and emotional transfer to the following generation. The lack of opportunities for effective support appears to be more likely. Fertility as such was not limited (e.g. through amenorrhea as a result of hunger or due to an extensive work load). On the 
contrary, in the socio-ecological context of the Krummhörn, the relatively long interbirth intervals tend to indicate contraceptive motivations (Kaiser 1998). An increase in fertility was not desired, as a rule, and even if it was, there was no need for external support.

On the other hand, infant mortality (that struck the families of workers, simple tradesmen and small farmers that have been studied in this analysis) is a factor limiting lifetime reproductive success; so maternal grandmothers should have had an opportunity to exert a positive influence. In the relatively prosperous and ecologically buffered Krummhörn, however, malnutrition was may not have been one of the usually very significant causal factors in infant and child mortality, so that here too, grandmothers hardly had an opportunity to reduce the mortality of their grandchildren by giving more of the goods they had acquired.

Interestingly, paternal grandmothers proved to have a disadvantageous effect: their presence increased infant mortality significantly during the first month of life. Our data are consistent both with the everyday knowledge that the relationship between wives and their mothers-in-law are structurally tension-laden and cause stress, and with the results of psychological research on the varying closeness between family members (Euler et al. 2001). What is popularly known as the "evil mother-in-law" could be the product of an evolutionary conflict of interest. But why is this the case? Why do mothers of adult sons put pressure on their daughters-in-law instead of supporting their reproduction? The sentiments and personal investment differences of grandparents ultimately reflect paternity certainty (Euler and Weitzel 1996), even if under high paternity certainty other factors may gain in importance (Pashoes 2000). Although the mating system of the Krummhörn population cannot be reconstructed with sufficient precision, there is no evidence that paternity uncertainty was an issue. There were hardly any divorces in this strictly Calvinist population. In view of the noticeable stability of marriages, we found no indication whatsoever for liberal sexual behavior, the consequences of which could have resulted in a significant reduction of paternity certainty. Therefore, it remains an open question what ultimately fuelled the in-law 
conflict. Even if our hominid ancestors lived in female kin networks in which long-lasting relationships between older women and their adult sons tended to be the exception (a scenario which is unlikely to be in accordance with the conventional view of male philopatry: Foley 1996), it remains unclear why mothers-in-law tended to have a negative impact. At best, we would have expected a zero effect on the reproduction of daughters-in-law.

\section{Conclusion}

The Krummhörn situation does not offer a good model for the unconditionally helpful grandmother. On the one hand, we find some support for the proposition of the grandmother hypothesis as proposed by Hawkes and colleagues (Blurton Jones et al. 1999, Hawkes et al. 1998, O'Connell et al. 1999) that assistance should flow through the female line. On the other hand, we also find evidence for the impairment of reproduction through the male line. Whatever the ultimate reason for the harmful impact of the daughter-in-law / mother-in-law relationship, it remains to be seen whether the helping grandmother may be a lethal motherin-law at the same time. If these findings can be generalized beyond the Krummhörn population, the hypothesis according to which the evolution of the postgenerative life span could be explained by the impact of grandmotherly kin-effects will have to be stated more precisely. The costs of social stress in the male descendency would have to be subtracted from the benefits of assistance in the female descendency.

\section{Acknowledgments}

We wish to extend our cordial thanks to Jim Vaupel and Jan Hoem for their friendly hospitality during our stay at the Max Planck Institute for Demographic Research in Rostock. Statistical advice came from Jutta Gampe and Jim Oeppen. Valuable comments came from Harald Euler, Kristen Hawkes, Ruth Mace, Monique Borgerhoff Mulder and Jocelyn Peccei. This paper has been prepared with the support of the Deutsche Forschungsgemeinschaft. 


\section{References}

Alvarez HP (2000) Grandmother hypothesis and primate life histories. Amer J Phys Anthrop 113: 435-450

Beise J (2001) Verhaltensökologie menschlichen Abwanderungsverhaltens - am Beispiel der historischen Bevölkerung der Krummhörn (Ostfriesland, 18. und 19. Jahrhundert). Doctoral thesis, University of Giessen. http://bibd.unigiessen.de/ghtm/2001/uni/d010060.htm

Bereszkei T (1998) Kinship network, direct childcare, and fertility among Hungarians and gypsies. Evol Hum Behav 19: 283-298

Blossfeld H-P, Rohwer G (1995) Techniques of Event History Modeling. New Approaches to Causal Analysis. Lawrance Erlbaum, Mahwah

Blurton Jones N, Hawkes K, O’Connell JF (1999) Some current ideas about the evolution of the human life history. In: Lee PC (ed.) Comparative Primate Socio-ecology. Cambridge University Press, Cambridge, pp. 140-166

Euler HA, Hoier S, Rohde PA (2001) Relationship-specific closeness of intergenerational family ties - Findings from evolutionary psychology and implications for models of cultural transmission. J Cross-cult Psychol 32: 147-158

Euler HA, Weitzel B (1996) Discriminative grandparental solicitude as reproductive strategy. Hum Nat 7: 39-59

Foley RA (1996) An evolutionary and chronological framework for human social behaviour. In: Runciman WG, Maynard Smith J, Dunbar RIM (eds.) Evolution of Social Behaviour Patterns in Primates and Man. Oxford University Press, Oxford, pp. 95-117

Hawkes K, O’Connell JF, Blurton Jones NG (1989) Hardworking Hadza grandmothers. In: Standen V, Foley RA (eds.) Comparative Socioecology - The Behavioural Ecology of Humans and Other Mammals. Blackwell, Oxford, pp. 341-366

Hawkes K, O'Connell JF, Blurton Jones NG (1997) Hadza women's time allocation, offspring provisioning, and the evolution of long postmenopausal life spans. Curr Anthrop 38: $551-577$

Hawkes K, O’Connell JF, Blurton Jones NG, Alvarez H, Charnov EL (1998) Grandmothering, menopause, and the evolution of human life histories. Proc Nat Acad Sci USA 95: 1336-1339

Hill K, Hurtado AM (1996) Ache Life History - The Ecology and Demography of a Foraging People. Aldine de Gruyter, Hawthorne

Hill K, Hurtado AM (1997) How much does grandma help? In: Betzig L (ed.) Human Nature - A Critical Reader. Oxford University Press, New York Oxford, pp. 140-143 
Kaiser I (1998) "Je lieber desto länger..." - Stilldauer und differentielles Elterninvestment in der Krummhörner Bevölkerung des 18. und 19. Jahrhunderts. Dipl.-Arb. Zentrum für Philosophie und Grundlagen der Wissenschaft, Universität Gießen

Kaplan H (1997) The evolution of the human life course. In: Wachter KW, Finch CE (eds.): Between Zeus and the Salmon - The Biodemography of Longevity. National Academy Press, Washington DC, pp. 175-211

Kaplan H, Hill K, Lancaster J, Hurtado AM (2000) A theory of human life history evolution: Diet, intelligence, and longevity. Evol Anthrop 9: 156-185

Leidy LE (1999) Menopause in evolutionary perspective. In: Trevathan WR, Smith EO, McKenna J (eds.) Evolutionary Medicine. Oxford University Press, New York pp. 407-427

Leidy LE, Godfrey LR, Sutherland MR (1998) Is follicular atresia biphasic? Fertility Sterility 70: 851-859

Mace R (2000) Evolutionary ecology of the human female life history. In: Robine J-M., Kirkwood T B L, Allard M (eds.) Sex and Longevity: Sexuality, Gender, Reproduction, Parenthood. Springer, Berlin \& Heidelberg pp. 59-73

Marlowe F (2000) The patriarch hypothesis - An alternative explanation of menopause. Hum Nat 11: 27-42

Meitzen A (1894) Der Boden und die landwirtschaftlichen Verhältnisse des Preussischen Staates. Parey, Berlin

O’Connell JF, Hawkes K, Blurton Jones NG (1999) Grandmothering and the evolution of Homo erectus. J Hum Evol 36: 461—485

Pashos A (2000) Does paternal uncertainty explain discriminative grandparental solicitude? A cross-cultural study in Greece and Germany. Evol Hum Behav 21: 97-109

Peccei JS (2001a) A critique of the grandmother hypotheses: Old and new. Amer J Hum Biol 13: 434-452 57

Peccei JS (2001b) Menopause: Adaptation or epiphenomenon? Evol Anthrop 10: 43—

Sear R, Mace R, McGregor IA (2000) Maternal grandmothers improve nutritional status and survival of children in rural Gambia. Proc Roy Soc Lond B 267: 1641-1647

Sear R, Steele F, McGregor IA, Mace R (in press) The effects of kin on child mortality in rural Gambia. Demography.

Voland E (1995) Reproductive decisions viewed from an evolutionarily informed historical demography. In: Dunbar RIM (ed.): Human Reproductive Decisions - Biological and Social Perspectives. MacMillan, Houndsmills London \& St. Martin's, New York, pp. 137-159 
Voland E (2000) Contributions of family reconstitution studies to evolutionary reproductive ecology. Evol Anthrop 9: 134-146

Voland E, Dunbar RIM (1995) Resource competition and reproduction - The relationship between economic and parental strategies in the Krummhörn population (17201874). Hum Nat 6: 33-49

Williams GC (1957) Pleiotropy, natural selection, and the evolution of senescence. Evolution 11: 398-411 
Figure 1: Plots of survivor functions (Kaplan-Meier estimates) for children relative to the constellation of their grandmothers (time axis in months; $\mathrm{N}=3771$ )

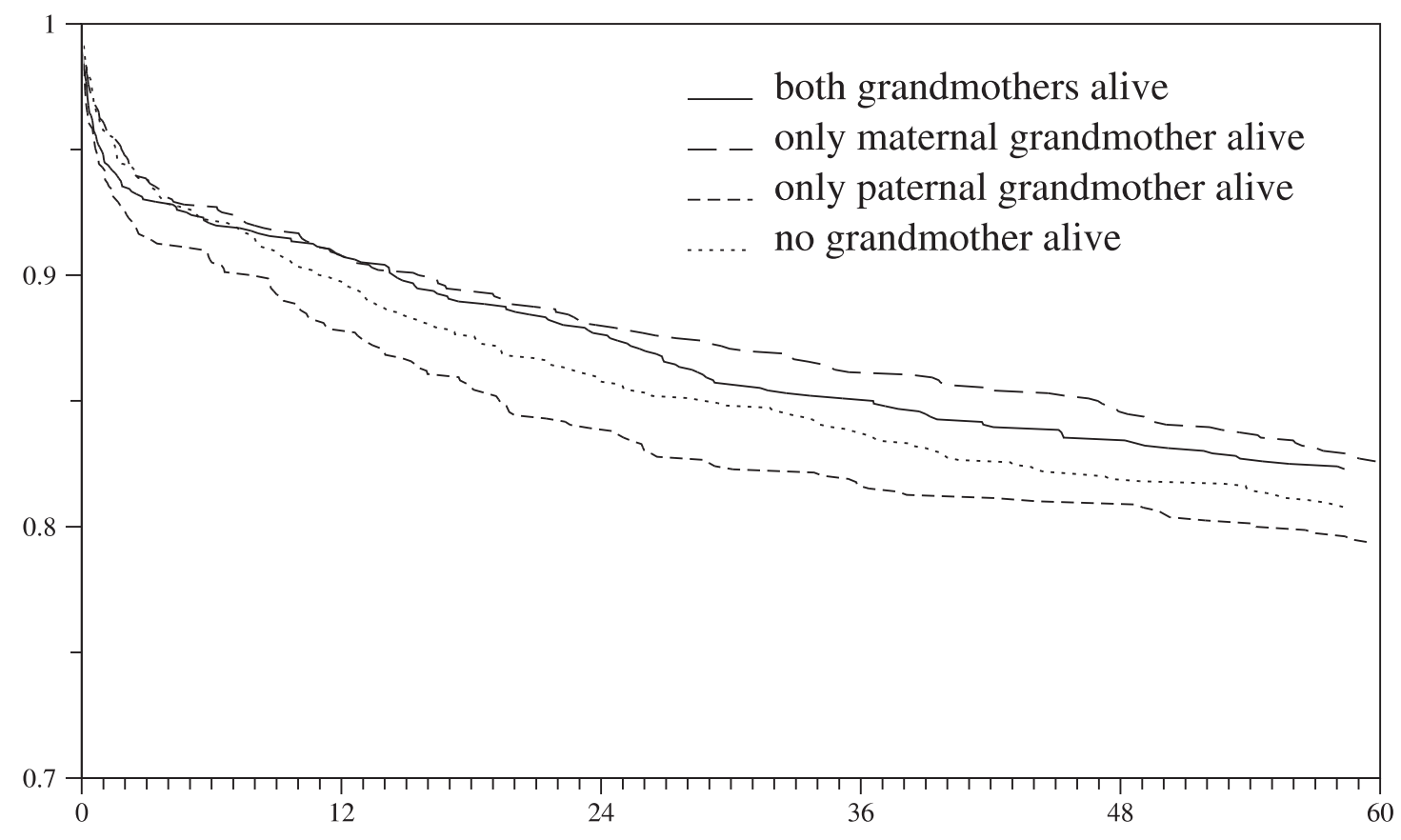


Table 1: ANOVA (SPSS) of interbirth intervals (mean $=2.94$ years; $\mathrm{sd}=1.35 ; \mathrm{n}=7,591$ ), intervals between two live births only.

\begin{tabular}{lcrrrr}
\hline Source & Type III Sum of Squares & \multicolumn{1}{c}{ Df } & Mean Square & \multicolumn{1}{c}{ F } & Sig. \\
\hline corrected model & $162.257(\mathrm{a})$ & 11 & 14.751 & 8.587 & 0.000 \\
\hline intercept & 80.533 & 1 & 80.533 & 46.883 & 0.000 \\
\hline age of father & 6.328 & 1 & 6.328 & 3.684 & 0.055 \\
\hline age of mother & 25.102 & 1 & 25.102 & 14.613 & 0.000 \\
\hline $\begin{array}{l}\text { constellation of } \\
\text { grandmothers }\end{array}$ & 3.316 & 3 & 1.105 & 0.643 & 0.587 \\
\hline $\begin{array}{l}\text { constellation of } \\
\text { grandfathers }\end{array}$ & 3.076 & 3 & 1.025 & 0.597 & 0.617 \\
\hline \# of living sibs & 35.020 & & & & \\
\hline error & 3876.947 & 3 & 11.673 & 6.796 & 0.000 \\
\hline total & 23857.640 & 2257 & 1.718 & & \\
\hline corrected total & 4039.204 & 2269 & & & \\
\hline
\end{tabular}

a R Squared $=.040$ (Adjusted R Squared $=.035$ ) 
Table 2: Logistic regression (SPSS) on parity progression probability $(\mathrm{n}=2,814)$.

\begin{tabular}{|c|c|c|c|c|c|c|c|c|}
\hline Variable & $\mathbf{n}$ & B & S.E. & Wald & df & Sig & $\mathbf{R}$ & $\operatorname{Exp}(B)$ \\
\hline \# living siblings & & 0.1600 & 0.0414 & 14.9406 & 1 & 0.0001 & 0.0683 & 1.1735 \\
\hline $\begin{array}{l}\text { grandmother } \\
\text { constellation, } \\
\text { reference: both } \\
\text { grandmothers dead }\end{array}$ & 895 & & & 4.2481 & 3 & 0.2359 & 0.0000 & \\
\hline $\begin{array}{l}\text { paternal grandmother } \\
\text { alive (1) }\end{array}$ & 563 & 0.1377 & 0.1597 & 0.7428 & 1 & 0.3888 & 0.0000 & 1.1476 \\
\hline $\begin{array}{l}\text { maternal grandmother } \\
\text { alive (2) }\end{array}$ & 736 & -0.0088 & 0.1431 & 0.0038 & 1 & 0.9508 & 0.0000 & 0.9912 \\
\hline $\begin{array}{l}\text { both grandmothers } \\
\text { alive (3) }\end{array}$ & 620 & 0.3432 & 0.1855 & 3.4213 & 1 & 0.0644 & 0.0226 & 1.4094 \\
\hline $\begin{array}{l}\text { grandfather } \\
\text { constellation, } \\
\text { reference: both } \\
\text { grandfathers dead }\end{array}$ & 1203 & & & 0.8314 & 3 & 0.8419 & 0.0000 & \\
\hline $\begin{array}{l}\text { paternal grandfather } \\
\text { alive(1) }\end{array}$ & 501 & -0.1059 & 0.1621 & 0.1621 & 1 & 0.5136 & 0.0000 & 0.8995 \\
\hline $\begin{array}{l}\text { maternal grandfather } \\
\text { alive (2) }\end{array}$ & 712 & -0.0441 & 0.1462 & 0.0911 & 1 & 0.7628 & 0.0000 & 0.9568 \\
\hline $\begin{array}{l}\text { both grandfathers alive } \\
\text { (3) }\end{array}$ & 388 & 0.0966 & 0.2252 & 0.1841 & 1 & 0.6679 & 0.0000 & 1.1014 \\
\hline $\begin{array}{l}\text { places of residence, } \\
\text { reference: natal family } \\
\text { and both grandparental } \\
\text { families live in the } \\
\text { same parish }\end{array}$ & 877 & & & 5.7925 & 3 & 0.1222 & 0.0000 & \\
\hline $\begin{array}{l}\text { residence of natal } \\
\text { family different from } \\
\text { both grandparental } \\
\text { families (1) }\end{array}$ & 329 & -0.4179 & 0.1915 & 4.7618 & 1 & 0.0291 & -0.0316 & 0.6584 \\
\hline $\begin{array}{l}\text { residence of paternal } \\
\text { grandparents different } \\
\text { from natal family (2) }\end{array}$ & 1141 & -0.0140 & 0.1398 & 0.0101 & 1 & 0.9200 & 0.0000 & 0.9861 \\
\hline $\begin{array}{l}\text { residence of maternal } \\
\text { grandparents different } \\
\text { from natal family (3) }\end{array}$ & 467 & -0.1250 & 0.1747 & 0.5121 & 1 & 0.4742 & 0.0000 & 0.8825 \\
\hline age of the mother & & -0.2281 & 0.0162 & 199.4675 & 1 & 0.0000 & -0.2669 & 0.7960 \\
\hline age of the father & & -0.0588 & 0.0112 & 27.6922 & 1 & 0.0000 & -0.0963 & 0.9429 \\
\hline year & & 0.2703 & 0.2089 & 1.6749 & 1 & 0.1956 & 0.0000 & 1.3104 \\
\hline year squared & & $-7.5 \mathrm{E}-05$ & $5.77 \mathrm{E}-05$ & 1.6994 & 1 & 0.1924 & 0.0000 & 0.0000 \\
\hline constant & & -231.616 & 188.8264 & 1.5046 & 1 & 0.2200 & & \\
\hline
\end{tabular}


Table 3: Effect of the grandmother constellation $(\operatorname{Exp}(B)$; reference group: both grandmothers are dead) on the probability of another birth (parity progression probability), by number of living siblings, including the same covariates as in Tab. 2 (note: $* * \mathrm{p}<0.01$ ).

\begin{tabular}{lccc}
\hline & \multicolumn{3}{c}{ number of living sibs } \\
& 0 & $1-3$ & $4+$ \\
\hline only paternal grandmother alive & 1.25 & 1.08 & 0.99 \\
\hline only maternal grandmother alive & 0.70 & 0.94 & 1.19 \\
\hline both grandmothers alive & 0.81 & 1.30 & $3.20^{* *}$ \\
\hline $\mathrm{N}$ & 680 & 1591 & 543 \\
\hline
\end{tabular}


Table 4: Results (as relative risk) of the transition rate model for infant mortality in the first five years of life (piecewise constant exponential models with period specific effects of covariates; for the covariates the levels of significance are noted as follows: ** $\mathrm{p}<0.01$, $* \mathrm{p}<0.05,+\mathrm{p}<0.1)$ Further explanations in the text.

\begin{tabular}{llll}
\hline $\begin{array}{l}\text { periods (age of child } \\
\text { in months) }\end{array}$ & $\begin{array}{l}\text { base line } \\
\text { mortality } \\
\text { hazard }\end{array}$ & $\begin{array}{l}\text { model 1 } \\
\text { grandmornal } \\
\text { (alive) }\end{array}$ & $\begin{array}{l}\text { paternal } \\
\text { grandmother } \\
\text { (alive) }\end{array}$ \\
\hline $0-1$ & 0.0540 & 1.0989 & $0.7334^{*}$ \\
\hline $1-6$ & 0.0063 & 1.1832 & 1.0590 \\
\hline $6-12$ & 0.0028 & $1.6202^{*}$ & 1.0942 \\
\hline $12-24$ & 0.0028 & $1.3731+$ & 0.9457 \\
\hline $24-36$ & 0.0024 & 1.0141 & 0.7909 \\
\hline $36-60$ & 0.0014 & 0.8621 & 1.2677 \\
\hline
\end{tabular}

Log-likelihood $=-4262.25 ; \mathrm{N}=3771$

\begin{tabular}{llll}
\hline $\begin{array}{l}\text { periods (age of child } \\
\text { in months) }\end{array}$ & $\begin{array}{l}\text { base line } \\
\text { mortality rate }\end{array}$ & $\begin{array}{l}\text { madernal 2(a) } \\
\text { grandmother } \\
\text { (alive) }\end{array}$ & $\begin{array}{l}\text { paternal } \\
\text { grandmother } \\
\text { (alive) }\end{array}$ \\
\hline $0-1$ & 0.0236 & 1.0693 & $0.6458^{* *}$ \\
\hline $1-6$ & 0.0027 & 1.2965 & 1.2156 \\
\hline $6-12$ & 0.0010 & $1.6403+$ & 0.8993 \\
\hline $12-24$ & 0.0015 & 1.2832 & 0.8161 \\
\hline $24-36$ & 0.0020 & 0.9776 & 0.8208 \\
\hline $36-60$ & 0.0012 & 0.9092 & 1.3096 \\
\hline
\end{tabular}

Log-likelihood $=-4042.04 ; \mathrm{N}=3642$

\begin{tabular}{llll}
\hline $\begin{array}{l}\text { periods (age of child } \\
\text { in months) }\end{array}$ & $\begin{array}{l}\text { base line } \\
\text { mortality rate }\end{array}$ & $\begin{array}{l}\text { model 3(b) } \\
\text { grandmother } \\
\text { (alive) }\end{array}$ & $\begin{array}{l}\text { paternal } \\
\text { grandmother } \\
\text { (alive) }\end{array}$ \\
\hline $0-1$ & 0.0242 & 1.1012 & $0.5405^{* *}$ \\
\hline $1-6$ & 0.0047 & $1.4373+$ & 1.0208 \\
\hline $6-12$ & 0.0013 & $1.7870^{*}$ & 0.8823 \\
\hline $12-24$ & 0.0016 & 1.2610 & 0.7402 \\
\hline $24-36$ & 0.0018 & 0.9461 & 0.8006 \\
\hline $36-60$ & 0.0016 & 1.0174 & $1.5354^{*}$ \\
\hline \multicolumn{4}{l}{} \\
\hline
\end{tabular}

a controlled for age of mother, number of living siblings, grandfather constellation, and cohort effects

b controlled for age of mother, number of living siblings, grandfather constellation, cohort effects, and place of residence 
Table 5: Results (as relative risks) of the same transition rate model like model 3 (see table 4) but using a combined variable concerning grandmothers' existence and her residence (the levels of significance are noted as follows: $* * p<0.01, * p<0.05,+p<0.1)$. The effects of a living grandmother are each compared to the effect of a corresponding dead grandmother. For further explanations, please see the text.

\begin{tabular}{llllll}
\hline \multicolumn{5}{c}{ model 4 } \\
\hline $\begin{array}{l}\text { periods (age } \\
\text { of child in } \\
\text { months) }\end{array}$ & $\begin{array}{l}\text { base line } \\
\text { mortality } \\
\text { hazard }\end{array}$ & $\begin{array}{l}\text { maternal gm lives } \\
\text { in the same } \\
\text { parish }\end{array}$ & $\begin{array}{l}\text { paternal gm lifferent } \\
\text { parish }\end{array}$ & $\begin{array}{l}\text { in the same } \\
\text { parish }\end{array}$ & $\begin{array}{l}\text { in a different } \\
\text { parish }\end{array}$ \\
\hline $0-1$ & 0.0168 & 0.8172 & 1.0017 & $2.4752^{* *}$ & $1.5879^{*}$ \\
\hline $1-6$ & 0.0048 & $0.6144+$ & 0.8216 & 0.5829 & 1.1068 \\
\hline $6-12$ & 0.0022 & 0.6677 & $0.4358+$ & 0.3556 & 1.4003 \\
\hline $12-24$ & 0.0014 & 0.7778 & 0.8222 & 1.2377 & 1.3741 \\
\hline $24-36$ & 0.0018 & 1.0153 & 1.0774 & $1.9383^{*}$ & 1.0099 \\
\hline $36-60$ & 0.0022 & 0.9070 & 1.0954 & 1.0611 & $0.4827^{* *}$ \\
\hline \multicolumn{5}{c}{ Log-likelihood $=-3407.78 ; \mathrm{N}=3095$} \\
\hline
\end{tabular}

Note: Due to statistical design, figures have a different meaning from those of table 4. Here figures above 1.0 indicate a relatively higher risk of infant mortality, while figures below 1.0 indicate a relatively lower risk of infant mortality. 